\title{
LXV. The $\gamma$-Rays of uranium and radium
}

\author{
Frederick Soddy M.A. \& Alexander S. Russell M.A. B.Sc.
}

To cite this article: Frederick Soddy M.A. \& Alexander S. Russell M.A. B.Sc. (1909) LXV. The $\gamma$-Rays of uranium and radium , Philosophical Magazine Series 6, 18:106, 620-649, DOI: 10.1080/14786441008636733

To link to this article: http://dx.doi.org/10.1080/14786441008636733

曲 Published online: 21 Apr 2009.

Submit your article to this journal ¿

Џ Article views: 6

Q View related articles $\sqsubset$

Citing articles: 5 View citing articles 5 
LXV. The $\gamma$-Rays of Uranium and Radium*. By Frederick Soddy, M.A., and Alexander S. Russell, M.A., B.Sc.†

\section{Introdurtion.}

TAVING at our disposal 50 kilograms of the purest I commercial uranyl nitrate, provided by the generosity of a friend, we have been enabled to study the radioactivity of uranium $\mathrm{X}$ on a considerably larger scale than previously attempted. This body, which was discovered by Sir William Crookes (Proc. Roy. Soc. 1900, lxvi. p. 409), was early recognized (Rutherford and Soddy, Phil. Mag. 1903, v. p. 441) as a disintegration product of uranium producing the whole of the $\beta$-rays but none of the $\alpha$-rays of that element. It has a period of average life of about 31 days. The period is long enough to allow of the separation of the greater part of the substance, even from a large quantity of uranium. When the activity of one product has decayed too far to work with, a fresh crop can be obtained by repeating the process. At each separation the uranyl nitrate is rendered purer, any fortuitous impurities present being eliminated, and as it is necessary in certain problems to be sure that no radioactive impurities are present initially, it is intended to carry out periodically a long series of such separations. The present work is concerned with the first three separations, carried out at intervals of about three months, and is devoted to a comparison of the $\gamma$-radiation of the active preparations separated, with the $\gamma$-rays of radium. We have found that, as in all other known cases, the $\gamma$-rays of uranium accompany the $\beta$-rays, both resulting entirely in the disintegration of uranium $X$. The results here recorded do not, however, bear out either of the rival views of the origin of the $\gamma$-rays, but rather indicate that the $\beta$-rays and $\gamma$-rays may be entirely distinct in origin.

Our knowledge of the $\gamma$-rays of uranium has previously been practically confined to the work of Eve, who examined the $\gamma$-rays of uranyl nitrate. Eve found in the first place that uranium only gave out about $\frac{1}{10}$ as much $\gamma$-radiation as thorium, though its $\beta$-radiation is, as is well known, very much more intense. Eve states that while the $\gamma$-rays of radium and thorium are of similar penetrating power, the $\gamma$-rays of uranium are much less penetrating, and are practically completely absorbed by $1 \mathrm{~cm}$. of lead. Over a range

* A preliminary account of part of this work was published in 'Nature,' March 4th, 1909, p. 7, and Phys. Zeit. 1909, x. p. 249.

$\dagger$ Communicated by the Authors. 
of from 0.26 to $0.94 \mathrm{~cm}$. of lead he found that the absorption proceeded according to an exponential law, the value of the absorption coefficient, $\lambda(\mathrm{cm} .)^{-1}$, being $1 * 4$. For radium he gives the values from 0.57 to 0.46 over a range of from $0.64 \mathrm{~cm}$. to $3 \cdot 0 \mathrm{~cm}$. of lead.

With our intensely active preparations of uranium $\mathrm{X}$ we have fully confirmed and extended Eve's statement with regard to the relative poverty of uranium in $\gamma$-rays as compared with the $\beta$-rays, and an accurate comparison of the ratio of the $\beta$ - to $\gamma$-rays for uranium $\mathrm{X}$ and for radium $\mathrm{C}$ is detailed in this paper. We may state the result here that radium gives 50 times more $\gamma$-rays in proportion to $\beta$-rays than is the case with uranium. We have found, however, that the $\gamma$-rays of uranium are not absorbed exponentially until after about $1 \mathrm{~cm}$. of lead, or an equivalent thickness of other substances, has been penetrated, and then they are similar in character, and only slightly inferior in penetrating power to the $\gamma$-rays of radium, the absorption coefficient being for most substances about 1.2 times greater over a range equivalent to from 1 to $5 \mathrm{~cm}$. of lead. For thicknesses less than $1 \mathrm{~cm}$. of lead the absorption curve is not exponential. The average slope of the curve, however, in a set of measurements with lead agreed approximately with Eve's value over a large part of the range he worked over. It is possible that a soft type of primary $\gamma$-rays is also present. but so far we have not been able to be sure of this, and this part of the subject is reserved for a future communication. In any case the $\gamma$-rays of uranium and radium examined over the same range are extremely similar in penetrating power and general character, and if a soft type of $\gamma$-rays from uranium exists, not represented in the $\gamma$-rays from radium, it is relatively feeble in character, and its existence is difficult to establish.

[The statement we made in preliminary communications that the absorption coefficient of the $\gamma$-rays of uranium was two and a half times greater than that of radium, which has unfortunately been quoted in abstracts, was based upon a published value for the radium rays which we have since found is altogether in error (Section 8). The ratios we ourselves have found for 13 substances are given in the last column of Table III. (p. 646).]

This being the case the great relative poverty in $\gamma$-rays of uranium compared to radium is a very remarkable fact. The $\beta$-rays of uranium are, like the uranium $\gamma$-rays, only slightly less penetrating than the corresponding radium rays. It is hardly possible to continue to regard the $\gamma$-ray as an 
$\mathrm{X}$-ray pulse generated by the expulsion of a $\beta$-ray electron from the disintegrating atom, a point of view which has been already seriously challenged by the alternative theory advocated by Bragg. But it is also difficult to accept the ready mutual convertibility of $\beta$-into $\gamma$-rays, and vice versa, which Bragg's theory requires, in face of the great similarity in nature and great difference in relative intensity which are shown by the $\beta$ - and $\gamma$-rays of radium and uranium. The most natural conclusion is that the two types are not interdependent.

The work here described falls under two heads. First, the preparation of the uranium $X$ and the comparison of its $\beta$ - and $\gamma$-activity with that of radium under defined conditions will be described. Secondly, an account will be given of the absorption of the $\gamma$-rays of uranium and radium under comparable conditions, which has been studied in considerable detail. The $\gamma$-rays are much more difficult to measure accurately than the less penetrating types, and there is much that is mysterious and unexplained in the actions they produce. In particular we may mention that the $\gamma$-ray ionization itself is not in all cases a constant quantity, but may suffer a regular progressive increase in amount from a minimum to a maximum when consecutive observations with the same disposition are made. This variation, which may give rise to errors as great as ten per cent. in an observation, must be guarded against in all measurements in which the $\gamma$-rays are concerned. So far we have been concerned mainly to find a method of working which will eliminate these fluctuations, and which will give consistent results. In this we have been successful, but the cause of the variation is still to be worked out. So far as the determinations of the absorption coefficients are concerned they have been done under conditions as nearly alike as possible for uranium and radium. Not much weight is to be attached to the absolute values of the coefficients, for there is necessarily a certain amount of arbitrariness in the choice of the experimental disposition. We have tried a great variety, and our conclusion is that though many give curves which are practically exponential within the limits of error, it is difficult to repeat $a b$ initio measurements of the absorption coefficient even under any one disposition with a variation of less than 5 per cent., while the actual value of the coefficient may depend considerably on the experimental disposition. 


\section{The Separation of Uranium $X$.}

We have found the original methods of Sir William Crookes (Proc. Roy. Soc. 1900, lxvi. p. 409) the most useful in the separation of uranium $X$. Without entering in the present paper into any detailed description of the methods employed and of the numerous trials which have led to their selection, it is necessary to give in outline some description of the process of separation which has been found most suitable in dealing with these large quantities of material. Crookes found that when uranyl nitrate was crystallized from water the photographic activity, which is due solely to the uranium X (Soddy, Trans. Chem. Soc. 1902, lxxxi.p. 860), of the crystals was enfeebled, while that of the mother-liquor was correspondingly enriched. The same observation was made by Godlewski five years later (Phil. Mag. 1905, x. p. 51), who stated, without giving any details, that it was possible in one crystallization to obtain ${ }_{7}^{6}$ of the total quantity of uranium $X$ in the mother-liquor. We found that the maximum separation of uranium $X$ was effected when about two-thirds of the total quantity of uranyl nitrate crystallized out from the solution on cooling. The motherliquor is then concentrated and the operation repeated several times until the amount of uranyl nitrate in the mother-liquor is reduced to about 100 grams. The uranium is then removed from this concentrate by adding excess of ammonium carbonate, in which uranium is soluble, leaving behind the uranium $X$ and the impurities as a precipitate. An attempt to use the acetone method of Moore and Schlundt to separate the uranium $\mathrm{X}$ from a concentrate in the first series of separations failed owing to the considerable quantities of impurities present, and led to much difficulty and loss of time. Dealing with quantities of material such that 10 per cent. of impurity represents an actual weight of 50 grams, ('rookes' crystallization and ammonium carbonate methods are still very effective, but indeed it is doubtful if any of the methods subsequently proposed are any better than these original ones in ordinary circumstances. It may be stated that the known methods of separation take advantages of peculiarities in the properties of uranium rather than of uraninm $X$. The latter does not appear to resemble any element very closely, and it is more difficult to separate it from admixture with other elements than from uranium.

The crystallization process employed may be illustrated from the case of the third separation after considerable experience had been acquired. Forty-seven kilograms of uranyl nitrate in four lots were dissolved in one-sixth of their weight 
of water, and the solutions heated over water-baths till a density of 2.02 was attained. The solutions were then poured into large evaporating basins and allowed to cool over night. When crystallization had set in completely the mother-liquor contained about one-third of the total weight of salt. The mother-liquors from each set of crystals were drained off, concentrated over the water-bath to the same density as before, poured out and allowed to crystallize slowly. The resulting mother-liquor is similarly treated, and so on until the amount of uranyl nitrate in the mother-liquor did not much exceed 100 grams. Usually the whole of the crystals so obtained would again be recrystallized, the mother-liquor from the first batch of crystals being added to the next and so on, while the end fractions from this second recrystallization usually were still sufficiently rich in uranium $X$ to be worth subjecting to a third recrystallization.

To test the amount of uranium $\bar{X}$ remaining in each batch of crystals a sample of about 40 grams is taken after thorough mixing. This is placed at a fixed distance below an electroscope provided with a base of aluminium foil $0.3 \mathrm{~mm}$. thick, and the leak it produces is compared with that produced by a similar sample of standard uranyl nitrate.

In a single operation arranged so that about two-thirds of the salt crystallizes it was found that the crystals retained from 15 to 30 per cent. of their initial quantity of uranium $\mathrm{X}$, so that of the total quantity of the latter all but from onesixth to one-ninth is concentrated in the mother-liquor. Oneseventh may be taken as an average fraction. In $n$ similar successive crystallizations the quantity of salt in the last mother-liquor is $\left(\frac{1}{3}\right)^{n}$ of the initial quantity, while the uranium $X$ contained therein corresponds to $\left(\frac{6}{7}\right)^{n}$ of the initial quantity. Thus after six successive crystallizations 50 kilograms would yield a final mother-liquor containing about 70 grams of uranyl nitrate together with the uranium $X$ from 20 kilograms of uranyl nitrate. In the second and third series of recrystallizations two further similar fractions would result with the uranium $X$ respectively of perhaps 10 kilograms and 5 kilograms. From the weights and activities of the various quantities of crystals obtained as the result of the process the fraction of the total uranium $X$ separated could be deduced. In the second separation about 80 per cent. and in the third about 72 per cent. of the uranium $\mathrm{X}$ was removed by crystallization.

The next step in the operation consisted in the removal of uranium from the concentrates by means of ammonium carbonate. Each concentrate as it was obtained was added to 
several litres of hot water, and treated with excess of a strong solution of ammonium carbonate containing ammonia. Too great excess is harmful, as uranyl ammonium carbonate is less soluble in ammonium carbonate than in water. Should all the uranium carbonate not redissolve the bulk of the supernatant liquor is drawn off and a further large quantity of hot water added. The liquor is then carefully filtered throngh an extracted filter on the pump and the precipitate washed with hot water, redissolved in dilute nitric acid and reprecipitated with excess of ammonium carbonate once or twice to ensure complete removal of the uranium. This process of separating uranium $X$ is a very efficient one, and in some cases the separation was extraordinarily perfect. Thus on one occasion to the uranium filtrate from a precipitate containing the combined quantities of uranium $\mathrm{X}$ from about 40 kilograms of uranyl nitrate a little iron chloride was added and the original process repeated. The $\beta$-activity of this iron precipitate was practically inappreciable. When it is considered that the actual weight of uranium $X$ in equilibrium with 50 kilograms of uranyl nitrate is below $.0005 \mathrm{mg}$., the removal from the uranium solution of the whole of this, all except perhaps $\overline{5}_{50000}^{1}$ part at most, in a single precipitation is a very remarkable operation. This is an exceptional case, but usually the amount of uranium $X$ in the filtrate was relatively small. In the first separation the combined uranium-X-containing precipitates weighed about $4.8 \mathrm{grams}$, in the second it was much less, and in the third it was only 0.65 gram. These precipitates, which naturally have considerable chemical interest, have not yet been exbaustively examined. It was not difficult to recognize two groups of substances (in about equal quantity in the first batch), the one consisting of common earths, largely alumina, and the other consisting of a pale yellow body more closely allied to uranium, and possibly a member of the tungsten family. In the last separation the precipitate consisted mainly of the latter substance. The separation of the two groups was simply effected by solution of the precipitate in nitric acid, and by the cautious addition of ammonia, below the quantity required for neutralization, until a yellow colour made its appearance. On setting aside for a few hours, the yellow body precipitated out, containing nearly all the uranium $\mathrm{X}$, leaving the alumina \&c. in the still acid solution. In this way further concentration of the uranium $X$ could be effected, but not much was gained by it. It has recently been noticed that this yellow compound is, like uranium carbonate, soluble in an excess of ammonium carbonate, but to a much 
less extent, and this observation suggests a simpler method of removing it from uranium $\mathrm{X}$ than has yet been tried.

For other experiments it was necessary to obtain the uranium $\mathrm{X}$ as the least possible quantity of material in the form of thin films which could be examined in an intense magnetic field. In the first and second separations this was effected by a long series of chemical operations, in which the uranium $X$ was removed from the solution of the precipitates in acid by successive additions of barium nitrate and sulphuric acid according to the method employed by Becquerel. The barium sulphate was then fused with alkali carbonates, and the well-washed barium earbonate, which contained the whole of the uranium $\mathrm{X}$, was dissolved in acid. A little iron chloride was added and precipitated with ammonium carbonate, the precipitate containing the uranium $X$. In the second separation the filter-papers and precipitates were ignited, brought on to three strips of micro-cover-glass each $75 \mathrm{~mm}$. long, $13 \mathrm{~mm}$. wide, and $0.12 \mathrm{~mm}$. thick. These were placed on a hot plate, a drop of hydrochloric acid added, and the solution made to cover the whole surface. The films were dried and heated till chlorine was given off, and were so obtained in a stable and tolerably coherent form. The weights of the films were 57,211 , and $11 \mathrm{mg}$. respectively, and their relative activity as $2: 1: 0 \cdot 12$. In this work they were kept in platinum trays placed side by side on a wood block. In the third separation the concentration was not pushed further after removing the uranium by ammonium carbonate. The burnt filter-papers were placed directly in the three platinum trays and treated with nitric acid (in one case hydrofluoric acid also to remove silica), the films formed being finally ignited at a red heat. They weigbed 285, 200, and 152 milligrams respectively, with relative activities as $1: 1: 0 \cdot 4$. The time absorbed in the second separation from the start to the preparation of the products in the final form was twelve days. In the third separation the first film was produced in $3 \cdot 3$ days, the second in 7 days, and the last in 9 days from the start. To settle certain points it was desirable to reduce the loss of material and time of preparation, rather than the weight of the product, to a minimum, and this was done by omitting the long process of further concentration adopted in the first and second separations. The increasing purity of the uranium made this possible. An indefinite loss of active material occurs in the numerous operations required to remove the unidentified yellow body, whereas it was required to deduce for one series the exact percentage of the 
equilibrium amount of uranium $\mathrm{X}$ contained in the preparations on the date of their comparison with radium.

Between the second and the third separations just described appeared the interesting paper by J. Danne, in Le Radium, 1909 , vi. p. 42 , on a new product in the uranium series, which he calls radio-uranium, intermediate between uranium and uranium $\mathrm{X}$, and acting as the direct parent of the latter. Mr. J. T. Smith kindly undertook for us at this stage a careful series of measurements over a considerable period of the $\beta$-activities of various products separated in the course of this work, and of the whole of the fractions of uranyl nitrate resulting from the second separation, with the object of ascertaining whether in any of them any concentration or impoverishment of the parent of uranium $\mathrm{X}$ had occurred. The results show, up to the present time, that the whole of the preparations lost or regained their $\beta$-activity perfectly normally, and no alteration in the normal amount of the parent of uranium $\mathrm{X}$ had been effected. We may thus conclude that none of the varied chemical operations used in the work have affected the power of uranium to produce uranium $\mathbf{X}$.

\section{Relative Intensity of the $\gamma$-Rays of Uranium and Radium.}

The bare uranium $X$ films, the preparation of which has just been described, lit up an X-ray screen brightly in the dark-room, and indeed the glow could still be seen in a fully lighted room when the screen was held in the shadow of the observer. The three bare films from the second separation together produced about the same effect when held under the screen as $6.7 \mathrm{mg}$. of radium bromide in a sealed thin glass tube, though on account of the difference in the area of the glow, and the absorption that occurred in the glass of the tube in the case of radium, this is merely a very rough comparison. But the $\gamma$-rays from these films were accurately compared with the $\gamma$-rays from $0.47 \mathrm{mg}$. of radium bromide, eight days after the last crystallization of the uranyl nitrate was started. The substances were placed $7.5 \mathrm{~cm}$. beneath the base of a brass electroscope, to which a thickness of $2 \cdot 5$ cms. of lead was clamped up to form a base. The $\gamma-$ activity of the uranium $\mathrm{X}$ was only equal to that of $0.056 \mathrm{mg}$. of radium bromide. Owing to the loss of active material during the numerous processes of concentration it was not possible to deduce accurately the amount of uranium $X$ in the preparations at the time of experiment, but the experiment clearly showed the great relative poverty of uranium in $\gamma$-rays as compared with $\beta$-rays. 
In the third separation careful check was kept of the weight and initial activity of each batch of crystals after the operation. From the time of accumulation of uranium $\mathrm{X}$ in the crystals between the second and third separations it was deduced that the initial content of uranium $X$ before separation was 98.5 per cent. of the equilibrium quantity. All but 28 per cent. of the equilibrium quantity of uranium $\mathrm{X}$ was separated initially, but at the date of the comparison of the uranium $\mathrm{X}$ with radium this had increased. From a curve of the regeneration of uranium $X$ with time, the initial $\beta$-activity of the crystals and their weight, it was deduced that on that date 44.35 per cent. of the equilibrium quantity of uranium $X$ was present in the crystals. The amount in the preparations was therefore $98 \cdot 5$ per cent. $-44 \cdot 35$ per cent., or 54.15 per cent. of the equilibrium quantity of 47 kilograms of uranyl nitrate. This is equal to the uranium $\mathrm{X}$ in $12 \cdot 13$ kilograms of metallic uranium in equilibrium. On a particular day, 8 days after the commencement of the last recrystallization, and 2 days after the finish of the separation, the $\gamma$-activity of the preparations was equivalent to the $\gamma$-activity of $0.094 \mathrm{mg}$. of radium bromide, measured through a thickness of $2.52 \mathrm{~cm}$. of lead. Now it will be shown later that the absorption coefficient for lead, for a range of from 1 to $5 \mathrm{~cm}$. of lead, for the radium $\gamma$-rays is 0.495 , and for the uranium $\gamma$-rays is $0.725(\mathrm{~cm} .)^{-1}$. It is true that for thicknesses below $1 \mathrm{~cm}$. of lead the absorption coefficients of the $\boldsymbol{\gamma}$-rays, both of uranium and radium, appear to be greater than those given, but for present purposes no great error is likely to be introduced if we calculate the ratio of the initial intensities of the $\gamma$-rays of uranium and radium from the observed intensities by means of these coefficients. Thus the initial $\gamma$-activity of the uranium $\mathrm{X}$ in equilibrium with $12 \cdot 13$ kilograms of metallic uranium is equal to the initial $\gamma$-activity of $0.17 \mathrm{mg}$. of radium bromide, or that from $1 \mathrm{kilogram}$ of uranium is equivalent to $\cdot 0138 \mathrm{mg}$.

It must be mentioned that the ultimate standard of comparison of radium in this case and throughout was a sealed tube containing $6.7 \mathrm{mg}$. of Giesel's radium bromide. The weight was taken with great care before sealing, but it is probable, since the compound was fairly old when weighed, that decomposition had occurred, and that the woight of radium therein was considerably greater than the formulaweight. Thus if the conversion into carbonate by the air had been complete the percentage of radium in the standard would be 79 , instead of $53 \cdot 5$ as initially. Taking provisionally a mean value of $66^{\circ} 6$ per cent. of radium in the sample the 
$\gamma$-activity of 1 kilogram of uranium is equal to that of $.009 \mathrm{mg}$. of radium, or radium gives about $10^{8}$ times more $\gamma$-rays than uranium.

\section{The Relative Value of the Ratio of $\gamma$ - to $\beta$-Rays for Uranium $\bar{X}$ and Radium $C$.}

It appeared very desirable to carry out an accurate determination of the relative value of the ratio of $\gamma$ - to $\beta$-rays for uranium and radium under strictly comparable conditions. Two electroscopes were used, one for the measurement of $\beta$-rays and the other for the $\gamma$-rays. The former had a base of very thin aluminium foil, $0.095 \mathrm{~mm}$. thick, and was set up so that the active preparations could be placed on the floor $119.5 \mathrm{~cm}$. below the base. The $\gamma$-ray electroscope was the lead cylindrical electroscope with a base of lead $.975 \mathrm{~cm}$. thick described under section 10 , and the preparations were placed $13.1 \mathrm{~cm}$. beneath the base. As the source of the $\beta$ - and $\gamma$-rays of radium was employed a film of radium $C$, prepared by exposing one side of a negatively charged copper disk to the radium emanation for 12.5 hours. After the exposure the disk was placed in a brass cell and a piece of $0.095 \mathrm{~mm}$. thick aluminium foil was cemented over the cell to prevent any possible escape of adhering emanation. A similar sheet of aluminium covered the uranium $X$ preparation. This consisted of one of the three preparations of the third separation, possessing 0.408 of the total activity. The date of these measurements was one week after those described in the last section.

Half an hour after the preparation of the film of radium $C$ alternative measurements of the $\beta$ - and $\gamma$-rays were taken over several hours, and from the decay curve obtained from the measurements the $\beta$-and $\gamma$-activity at any time could be readily deduced. Other similar measurements were also made of the $\beta$-rays when the base of the electroscope consisted of a sheet of aluminium foil $0.9 \mathrm{~mm}$. thick, and of the $\gamma$-rays when the base of the electroscope consisted of plates of aluminium 4 and $6 \mathrm{~mm}$. thick. The latter thickness is sufficient to reduce the $\beta$-radiation of both elements to an inappreciable amount. The former, however, was found to allow a little of the $\beta$-radiation of radium only to get through. For all dispositions measurements were also taken with the uranium $\mathrm{X}$. In this way the relative ratio of the $\gamma$ - to $\beta$ activity of uranium and radium under comparable conditions was ascertained. It may be assumed that $0.195 \mathrm{~mm}$. of aluminium cats down the $\beta$-rays of uranium and radium to practically the same extent, since the absorption is but small. 
The initial values for the $\gamma$-ravs before penetrating the $0.975 \mathrm{~cm}$. of lead were deduced by means of the absorption coefficients referred to in the last section. It was found that under the conditions described the ratio of $\beta$-rays to $\gamma$-rays (corrected for absorption in $9975 \mathrm{~cm}$. lead) was for radium $C$ $0 \cdot 283$ and for uranium $X 14.05$. The relative value of the ratio of $\beta$ - to $\gamma$-rays for uranium $\mathrm{X}$ in terms of this ratio for radium $\mathrm{C}$ as unity is thus $49 \cdot 7$. Uncorrected for absorption this ratio is 62 . It therefore appears that the initial $\gamma$-radiation of uranium as compared with its $\beta$-radiation is fifty times less than for the case of radium. When the $\beta$-rays were measured through $0.995 \mathrm{~mm}$. of aluminium instead of $0.195 \mathrm{~mm}$. the ratio was 0.58 times $49 \cdot 7$, which is to be expected, since the $\beta$-rays of uranium are rather less penetrating than those of radium. When the $\gamma$-rays through $6 \mathrm{~mm}$. of aluminium were compared with the $\beta$-rays through $0.19 \mathrm{~mm}$. of aluminium the result was 3.5 times more favourable to the $\gamma$-rays of uranium than through $0.975 \mathrm{~cm}$. of lead. Under these conditions the $\gamma$-radiation as compared with the $\beta$-radiation is for uranium about 18 times less than for radium. This appears to be evidence that uranium gives a soft $\gamma$-radiation not given by radium, but the point will be discussed in more detail in a subsequent communication.

The $\gamma$-activity of a sealed tube containing $0.47 \mathrm{mg}$. of radium bromide was taken at the same time and with the same instrument as the other measurements. This gave an entirely independent estimate of the relative $\boldsymbol{\gamma}$-activity of the uranium $\mathrm{X}$ preparations in terms of radium bromide through a much smaller thickness of lead than was used in the measurement a week previously. Nevertheless the result was nearly the same. The uranium $X$ in equilibrium with 1 kilogram of uranium corresponded in initial $\gamma$-activity to $0.0150 \mathrm{mg}$. radium bromide, as compared with $0.0138 \mathrm{mg}$. found previously. The former value is probably the nearer to the truth.

\section{The Connexion between the $\beta$ - and $\gamma$-Rays of Uranium $X$.}

On account of this great relative poverty of uranium in $\boldsymbol{\gamma}$-radiation it was decided to test more closely the view that the $\gamma$-radiation accompanied the $\beta$-radiation in the disintegration of uranium $X$. In the first place the $\gamma$-activity of a kilogram of uranyl nitrate, the $\beta$-activity of which had been enfeebled to a known extent by crystallization, was compared with the $\gamma$-activity of another kilogram of uranyl nitrate in equilibrium with uranium $X$. For this purpose the substances were placed immediately below an electroscope, the 
base of which consisted of a sheet of iron sufficient to absorb the $\beta$-radiation completely. The crystals just filled a cylindrical jar of about the diameter of the electroscope. It was found that the $\gamma$-radiation in the two substances was proportional to the $\beta$-radiation, indicating that the whole of the $\gamma$-radiation is derived from the uranium $X$. The effects measured were small, and naturally no great accuracy was attained.

The next step was to determine the rate of decay of the $\gamma$-radiation of uranium $X$ as accurately as possible. Preliminary experiments with the preparations of the second separation had shown that the period of the decay was at any rate approximately the same as that of the $\beta$-rays. Measurements of each of the three preparations of the third separation bave shown that the decay of the $\gamma$-radiation is exponential from the date of separation up to the present date (30 days). The value of the coefficient of decay was found to be 0.029 (day) ${ }^{-1}$, which agrees as closely as is to be expected with the value found for the $\beta$-rays $0 \cdot 031$ (Rutherford \& Soddy, Phil. Mag. 1903, v. p. 444).

Although these results, so far as they go, confirm the view that the $\gamma$-radiation accompanies the $\beta$-radiation in the disintegration of uranium $X$, there seems no escape from the conclusion that the $\gamma$-rays are a primary radiation due to the disintegration of the atom, and not a secondary radiation accompanying the expulsion of the $\beta$-particle. Since for two elements the $\beta$ - and $\gamma$-radiations of which, although similar, each to each, in general character, yet differ in relative intensity in the ratio of 50 to 1 , there seems no incongruity in contemplating the possibility of a $\beta$-radiation wholly unaccompanied by $\gamma$-radiation. One may even hazard the suggestion that possibly $\beta$-rays will be found to accompany the change of uranium $\dot{X}$ into radium while $\gamma$-rays accompany the change of uranium $\mathrm{X}$ into actinium. Although there is no evidence at present in favour of this there is equally nothing to be urged against it.

\section{$5 \mathrm{~A}$.}

[Later results for the decay of the $\gamma$-rays over a period of 80 days are now available. For the last 49 days the preparations have not been used in other experiments, or disturbed between the measurements. The value of $\lambda$ (day) ${ }^{-1}$ over this period has been found to be 0.028 . This is about 10 per cent. smaller than the original value found for the decay of the $\beta$-rays, but it is possible that the discrepancy is due to an error in the determination of this latter constant. We are now investigating this point.] 


\section{Absorption of Uranium $\gamma$-Rays by Matter. (First Series.)}

After preliminary trials with the uranium $\mathrm{X}$ of the first separation, a careful series of measurements was carried out with the preparations of the second separation on the absorption of the $\gamma$-rays by various substances. The selection of the particular experimental disposition employed involves necessarily a certain amount of arbitrariness, for as is wellknown the ionization produced by $\gamma$-rays results largely from the secondary radiations it sets up in the walls of the measuring instrument. Again, one may, while keeping the distance between the active material and the electroscope constant, place the absorbing screens either directly over the active material, or directly under the electroscope, or at any intermediate position. Or, one may have the active material near to the electroscope and include a large cone of rays, or far away, and work with practically a parallel beam. It is curious that in all the published measurements of the absorption of $\gamma$-rays, only Wigger (Jahr. Radioakt. 1905, ii. p. 430) has given full and precise information on these important points.

The electroscope employed was a cylindrical brass one of internal height $12.8 \mathrm{~cm}$., internal diameter $10.52 \mathrm{~cm}$., and of wall thickness $0.145 \mathrm{~cm}$. It was supported by four brass pillars $15.8 \mathrm{~cm}$. above a permanent base-board. Most of the absorbing plates used were $11 \mathrm{~cm}$. square, but lead and brass were in the form of circular disks, 11 and $12.7 \mathrm{~cm}$. diameter respectively. They were clamped up tightly to the bottom of the electroscope forming its base. When the absorbers were insulators the upper surface was covered with aluminium foil, $0.0035 \mathrm{~mm}$. thick. For light substances, with a density below 2, a plate of lead $1 \cdot 26 \mathrm{~cm}$. thick formed the base of the electroscope. The uranium X mounted on one of two wooden stands, of heights 1.2 and $7.55 \mathrm{~cm}$. respectively, according to the nature and amount of the absorbing material under investigation, was placed underneath the electroscope. The following table gives the results. The first column gives the number of the experiment, the second the distance of the preparation from the base of the electroscope, the third the absorbing material, the fourth its density $d$, the fifth the range over which the absorption is exponential, the sixth the value of the absorption coefficient $\lambda(\mathrm{cm} .)^{-1}$, and the seventh the mean value of the ratio $\lambda / d \times 100$. Some of these results are plotted as curves in fig. 1 . The ordinates represent logarithms of the ionization leak, in divisions per minute corrected for natural leak, and the abscissa are thicknesses in $\mathrm{cm}$. To separate the curves in the figure from 
one another an arbitrary constant has been added to the logarithm of the ionization leak in some cases. The numbers on the curves refer to the numbers in the first column of the table.

For mercury a different arrangement had necessarily to be adopted. A circular hole $11.5 \mathrm{~cm}$, in diameter was cut in a block of wood $4 \mathrm{~cm}$. thick, and to the bottom was fixed a circular plate of glass about $3 \mathrm{~mm}$. thick. This was provided with levelling screws, and placed close over the preparations. It was levelled and sufficient mercury placed in it completely to cover the surface, and then weighed amounts of mercury were added or withdrawn. In experiments Nos. 1 and 2 the base of the electroscope was a plate of lead $1.2 \mathrm{~cm}$. thick. In experiment No. 3 it was two sheets of tinfoil. The results in the latter case lie on a continuous curve convex to the origin, and no one value can be assigned to $\lambda$.

\section{TABLE I.-Uranium X. $\gamma$-Rays.}

Brass Electroscope, absorbing plates forming base.

\begin{tabular}{|c|c|c|c|c|c|c|}
\hline No. & Distance. & Material. & Density. & Range (cm.). & $\lambda(\mathrm{cm} .)^{-1}$. & $\lambda / d \times 100$ \\
\hline $\left.\begin{array}{r}1 \\
2 \\
3 \\
4 \\
5 \\
6 \\
7 \\
8 \\
9 \\
10 \\
11 \\
12 \\
13 \\
15 \\
14 \\
16\end{array}\right\}$ & $\begin{array}{c}", \\
14 " 63 \\
", \\
",\end{array}$ & $\begin{array}{l}\text { Brass. } \\
\text { Iron. } \\
\text { Tin. } \\
\text { Zine. } \\
\text { Slate. } \\
\text { Aluminium. } \\
\text { Glass. }\end{array}$ & $\begin{array}{r}13.59 \\
11 \cdot 40 \\
8 \cdot 81 \\
8.35\end{array}$ & 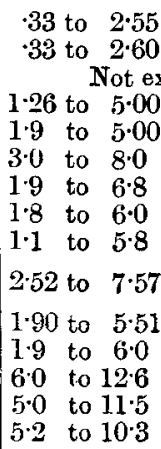 & $\begin{array}{c}\cdot 687 \\
\cdot 760 \\
\text { ponential. } \\
\cdot 634 \\
.620 \\
.413 \\
.430 \\
\cdot 410 \\
.443 \\
.335 \\
.394 \\
.351 \\
.373 \\
.158 \\
.148 \\
\cdot 165\end{array}$ & $\begin{array}{l}5 \cdot 56 \\
5 \cdot 44 \\
4 \cdot 69 \\
4 \cdot 88 \\
4 \cdot 91 \\
5 \cdot 30 \\
4 \cdot 40 \\
5 \cdot 17 \\
4 \cdot 84 \\
5 \cdot 27 \\
5 \cdot 54 \\
5 \cdot 34 \\
6 \cdot 54\end{array}$ \\
\hline
\end{tabular}

Below this the base consisted of $1 \cdot 26 \mathrm{~cm}$. of Lead.

\begin{tabular}{|c|l|l|l|l|l|l|}
\hline 18 & & MagnesiaBrick. & $1 \cdot 92$ & $2 \cdot 7$ to $11 \cdot 8$ & $\cdot 1029$ & $\mathbf{5} \cdot 36$ \\
17 & $"$ & Sulphur. & $1 \cdot 79$ & $2 \cdot 2$ to $11 \cdot 6$ & $\cdot 1046$ & $\mathbf{5} \cdot 84$ \\
19 & $"$ & Paraffin Wax. & $\mathbf{0} 862$ & 3.8 to $11 \cdot 4$ & $\cdot 0576$ & $\mathbf{6} \cdot 68$ \\
20 & $"$ & Pine-Wood. & 0.386 & $2 \cdot 0$ to $11 \cdot 5$ & $\cdot 0214$ & $\mathbf{5 . 5 4}$ \\
\hline
\end{tabular}

Mean value of $\lambda / d=\cdot 0536$.

Phil. Mag. S. 6. Vol. 18. No. 106. Oct. 1909 . 2 U 
634 Messrs. F. Soddy and A. S. Russell on the

It will be seen from the other curves that after a certain initial thickness of matter has been penetrated, corresponding

Fig. 1.

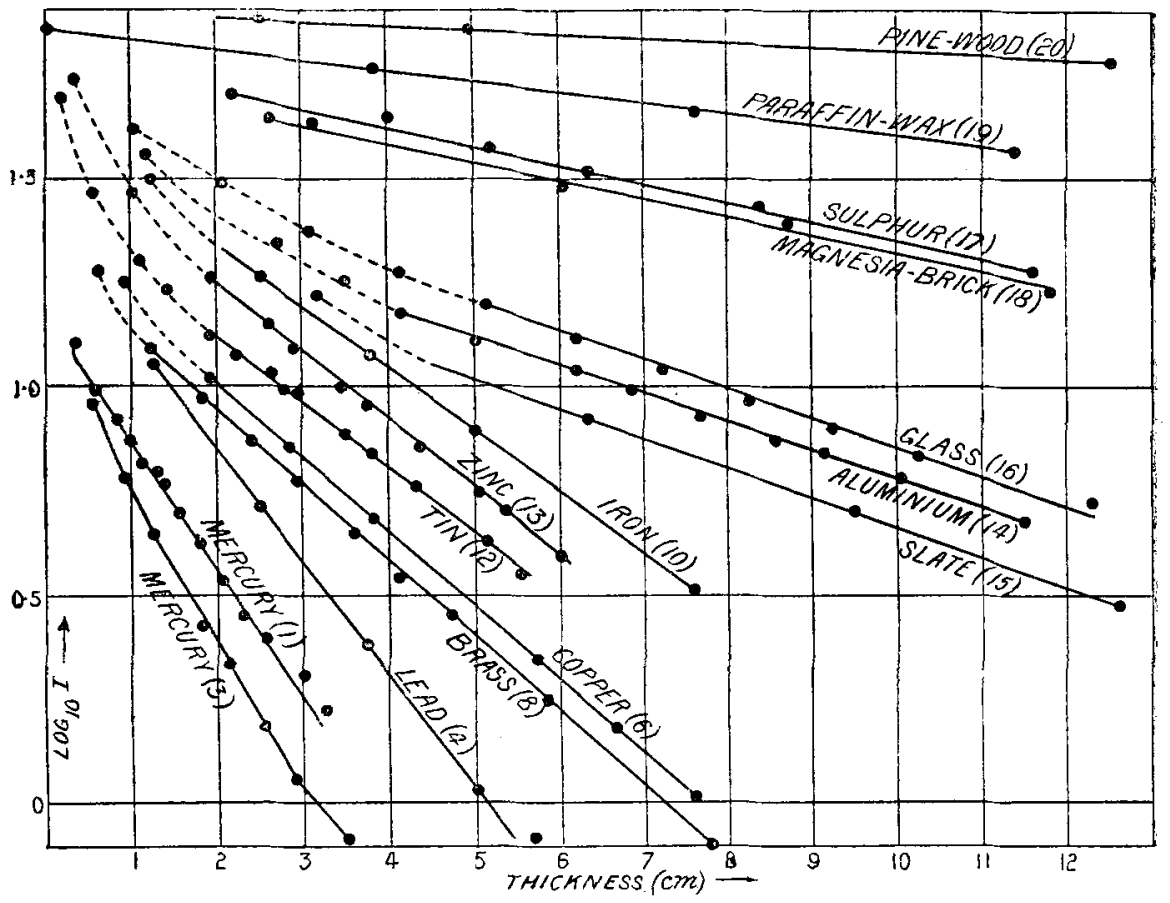

to $1 \mathrm{~cm}$. of lead, or an equivalent thickness of other substances, the absorption follows an exponential law represented by the equation

$$
\frac{\mathrm{I}_{\left(t_{1}\right)}}{\overline{\mathrm{I}}_{\left(t_{\mathbf{2}}\right)}}=\epsilon^{-\lambda\left(t_{1}-t_{2}\right)},
$$

where $t_{1}$ and $t_{2}$ refer to thicknesses in centimetres, $I_{\left(t_{1}\right)}$ and $I_{\left(t_{2)}\right)}$ to the corresponding ionizations, and $\lambda$ is a constant, which is usually termed "the absorption coefficient." Owing to the obliquity of part of the beam this absorption coefficient departs slightly from the true absorption coefficient corresponding to the $\lambda$ of the theoretical equation

$$
\frac{d \mathrm{I}}{d t}=-\lambda \mathrm{I}
$$

which represents the exponential absorption of a parallel homogeneous radiation passing through the absorbing plate normally to its surface. It can be shown, for example, to be 
about 25 per cent. greater over the whole range for the disposition described in detail in section 10. For thicknesses less than $1 \mathrm{~cm}$. of lead the curves are no longer exponential, and the value of $\lambda$ apparently increases. The study of this part of the range forms the subject of a separate communication.

It will be seen that as a general result the experimental values of $\lambda / d$ are nearly the same for all substances, the mean value being 0.0536 . The departures of the values of $\lambda / d$ from this mean are, however, greater than should be the case if they were due merely to errors of observation. Indeed the variations seemed not to be due so much to differences in the metals, as different results were obtained for different series of observations on the same metals, as to other unexplained causes. The extreme values for $\lambda / d$ vary between $\cdot 0668$ and $\cdot 0440$, a difference of about 20 per cent. on either side of the mean value.

Beyond a thickness of $5 \mathrm{~cm}$. of lead, or an equivalent thickness of mercury, the absorption appeared to be less than the normal. At this range, however, the effects produced are of the same order of magnitude as the natural leak of the instrument, and are too small to be measured with any certainty. Subsequent experiments with the more active preparations of the third separation failed to establish beyond doubt any alteration in the value of the absorption coefficient.

The disposition employed in this series is a troublesome one to work with in practice, but in our opinion the general results obtained are, from a theoretical point of view, of equal value to those obtained with another disposition detailed in section 11 .

\section{Variation of the Ionization produced by $\gamma$-Rays.}

In order to compare directly the $y$-rays of uranium with those of radium and to obtain further light on the variations referred to, experiments were now undertaken with radium. It was found, in the first place, that the errors of observation were reduced by removing the source of light a considerable distance from the electroscope, and interposing a sheet of ground glass between it and the electroscope. A thin cardboard cover also was placed over the electroscope which was removed only when the leaf system was being charged. This hood had the effect of maintaining a constant temperature around the wall of the electroscope while its presence did not affect the leak of the instrument. In the second place, a very curious effect was noticed, first in working with the more powerful $\gamma$-rays from radium. If the time for the leaf to cross the scale was taken and the experiment repeated a number 
of times, the rate of leak gradually increased, considerably at first and then less rapidly, until a maximum rate was reached. This phenomenon was got with different electroscopes, different absorbing plates, and with both radium and uranium $X$. The sign of the charge on the leaf did not seem to produce any effect. The maximum rate of leak was found in all cases to be about 12 per cent. greater than the minimum. The cause of the steady increase in the rate of leak to a maximum remains unknown. We cannot at present give any explanation of it. In certain new forms of ionizationvessels we are now working with it is not shown. In this connexion may be recalled an experiment by G. Jaffé ( $A n n$. Phys. 1908, xxv. p. 271), who found it to be impossible to obtain complete saturation in air at atmospheric pressure ionized by the $\gamma$-rays of radium, even with a potential gradient of 5000 volts per cm. Kleeman (Phil. Mag. 1907, xiv. p. 622) also called attention to gradual fluctuations in magnitude of 5 to 10 per cent. in the values of the leaks obtained by using a differential method with two ionization-chambers and a steady sonrce of $\gamma$-rays. He suggested that the emanation might be coming off from the radium salt intermittently, causing alterations in the centre of origin of the $\gamma$-rays. This certainly does not apply to our case, for the effect is shown also by the $\gamma$-rays of uranium $X$, and the irregularities moreover are quite definite. The effect depends on the maintenance during successive observations of the charge on the leaf system; for if with everything in place the whole be left undisturbed for a quarter of an hour, and then a series of consecutive observations are taken without pause, the minimum leak is first obtained, and this gradually increases to the maximum. Thus in one experiment $6.7 \mathrm{mg}$. of radium bromide in a sealed tuhe was placed below a brass electroscope, the base of which consisted of $6 \cdot 28 \mathrm{~cm}$. of lead, and everything was left for ten minutes. Consecutive observations, then taken over 100 divisions of the eyepiece scale, were, in divisions per minute, 111, 114, 118, 120, 120, 122, $123 \cdot 5,124,124 \cdot 2,125,125,125$. If now the radium were held up to the side of the instrument for a minute without recharging, and the observations repeated, the minimum leak was again obtained, and this again increased to the maximum. In practice it is easier and quicker thus to obtain the minimum leak than the maximum leak, and we have so far been concerned to employ a method of working which shall avoid these errors and give consistent results. This is achieved in the following manner.

After each observation, the leaf being still partially charged, $6.7 \mathrm{mg}$, of radium bromide in a sealed tube is placed near 
a window of the electroscope and the air within thoroughly ionized for about 40 seconds. The radium is then removed and the leaf charged up but slightly more than is necessary to get it onto the scale.

The leak so obtained is the minimum leak, and seems to be, if not the true, at least a consistent measure of the ionization of the $\gamma$-rays from the source used. The leak with the new electroscope of lead described later is quite constant for a particular disposition over any one day, leaks of 12 minutes duration rarely varying by more than three or four seconds. Also the values of $\lambda$ obtained by this method for any one substance on different days do not usually differ by more than one or two per cent. After this method of working was found, the measurement of ionization leaks due to $\gamma$-rays became almost as simple as in the case of the other radiations, whereas before they were very uncertain and variable. Without some such precautions being employed $\gamma$-ray measurements can hardly be depended upon to 10 per cent.

8. Absorption of $\boldsymbol{\gamma}$-Rays of Radium under Various Conditions.

The published values of $\lambda$ for the $\gamma$-rays of radium show considerable differences among themselves, and we have carried out a large number of experiments to determine whether this value depends on the conditions. McClelland (Phil. Mag. 1904, viii. p. 70) and Eve (P'hys. Zeil. 1907, viii. p. 183) agree fairly closely. The latter gives the value of $\lambda$ as varying from 0.56 to 0.46 over a range of from 64 to $3 \mathrm{~cm}$. of lead. Wigger, who worked over the range from $2 \cdot 8$ to $5 \mathrm{~cm}$. of lead with a peculiar apparatus, found the value 0.241 . Kleeman (Phil. Mag. 1907, xiv. p. 643) came to the conclusion, from experiments on the secondary cathode rays generated by $\gamma$-rays, that the latter must consist of three groups of rays. Madsen recently (Phil. Mag. 1909, xvii. p. 447) concluded that the $\gamma$-rays consisted of two homogeneous radiations possessing values for $\lambda / d$, independent of the nature of the absorbing substance, 0.028 and 0.12 respectively. Thus, for lead $\lambda$ has the values 0.32 and 1.36. Since the present work was done Y. Tuomikoski has published (Phys. Zeit. 1909, x. p. 372) a determination of $\lambda$ for $\gamma$-rays of radium over a range up to $18 \mathrm{~cm}$. of lead. He gives the following values :-

\begin{tabular}{|c|c|c|c|c|c|c|}
\hline $\begin{array}{c}\text { Thickness }\left\{\begin{array}{c}\text { from } \\
(\mathrm{cm} .)\end{array}\right. \\
\text { to }\end{array}$ & $\begin{array}{r}\cdot 4 \\
1.0\end{array}$ & $\begin{array}{l}1 \cdot 0 \\
2 \cdot 2\end{array}$ & $\begin{array}{l}2 \cdot 2 \\
5 \cdot 4\end{array}$ & $\begin{array}{r}5 \cdot 4 \\
12 \cdot 0\end{array}$ & $\begin{array}{l}12 \cdot 0 \\
15 \cdot 8\end{array}$ & $\begin{array}{l}150^{\circ} \\
180^{\circ}\end{array}$ \\
\hline$\lambda(\mathrm{cm} .)^{-1} \ldots \ldots \ldots$ & 70 & .58 & .52 & $\cdot 50$ & $\cdot 39$ & $\cdot 25$ \\
\hline
\end{tabular}


From the paper, which is merely a preliminary account, no conclusion can be formed, in view of the results to be given in this section, as to whether the convexity of the absorption curve to the origin, which these numbers disclose, is due to a real change in the value of the absorption coefficient.

We obtained for several dispositions results similar to those given by Eve and McClelland, and in no case near Wigger's lower value, so we repeated the latter's work as closely as possible. The apparatus consisted of a vertical brass cylinder $105 \mathrm{~cm}$. long, $4.5 \mathrm{~cm}$. inside diameter, $0.5 \mathrm{~mm}$. wall thickness provided with a central electrode $95 \mathrm{~cm}$. long passing through an insulator and directly connecting with a leaf system inside an ordinary brass electroscope. The lead plates were placed over the open top end of the cylinder and the radium was fixed at a definite height above. The capacity of the arrangement was 30 times greater than that of an ordinary leaf system. In an experiment with the radium $56 \mathrm{~mm}$. from the top of the cylinder, as used by Wigger, the absorption proceeded exponentially from a range of $2 \cdot 8$ to $4 \cdot 7 \mathrm{~cm}$. of lead, the value of the absorption coefficient $\lambda$ being $0 \cdot 479$, instead of 0.241 as stated by him. Wigger, however, appears to have calculated his results wrongly. He does not state the natural leak of his instrument; but neglecting this and recalculating from his own observations gave a value similar to what we obtained experimentally.

The effect of increasing the distance of the radium from the end of the cylinder to $78 \mathrm{~mm}$. and $100 \mathrm{~mm}$. was then tried. The leak fell off with great rapidity as the distance of the radium was increased, showing that only a few $\mathrm{cm}$. of the top end of the long cylinder could be effective in contributing to the ionization. The curves obtained over the same range as before were quite exponential, but the values of $\lambda$ were now different, being 0.438 at $78 \mathrm{~mm}$. and 0.393 at $100 \mathrm{~mm}$. This effect of the variation of $\lambda$ with the distance of the source of radiation from the ionization-chamber was then investigated with a common form of apparatus. The brass electroscope, used in the measurements of section 6 , was mounted on brass pillars on a wooden plank one end of which was supported on the slate bench while the other was supported by two long legs standing on the floor. A large hole was cut in the plank so as to allow free passage of radiations from beneath the table into the electroscope. The base of the electroscope was of lead $2.840 \mathrm{~cm}$. thick clamped up as before. It was found that with $5 \mathrm{~cm}$. of lead over the radium placed on the floor and $2.84 \mathrm{~cm}$. as base the leak was 
considerably less than if all the metal was clamped up to the base and the radium tube left bare. The difference in the leaks due to the two dispositions it would seem natural to ascribe to the generation of secondary rays in the slate bench and elsewhere sufficiently penetrating to get through the walls of the electroscope, which are produced in greater intensity in the first case than in the second. In consequence the lead, all except the $2.84 \mathrm{~cm}$. forming the base, was placed directly

Fig. 2.

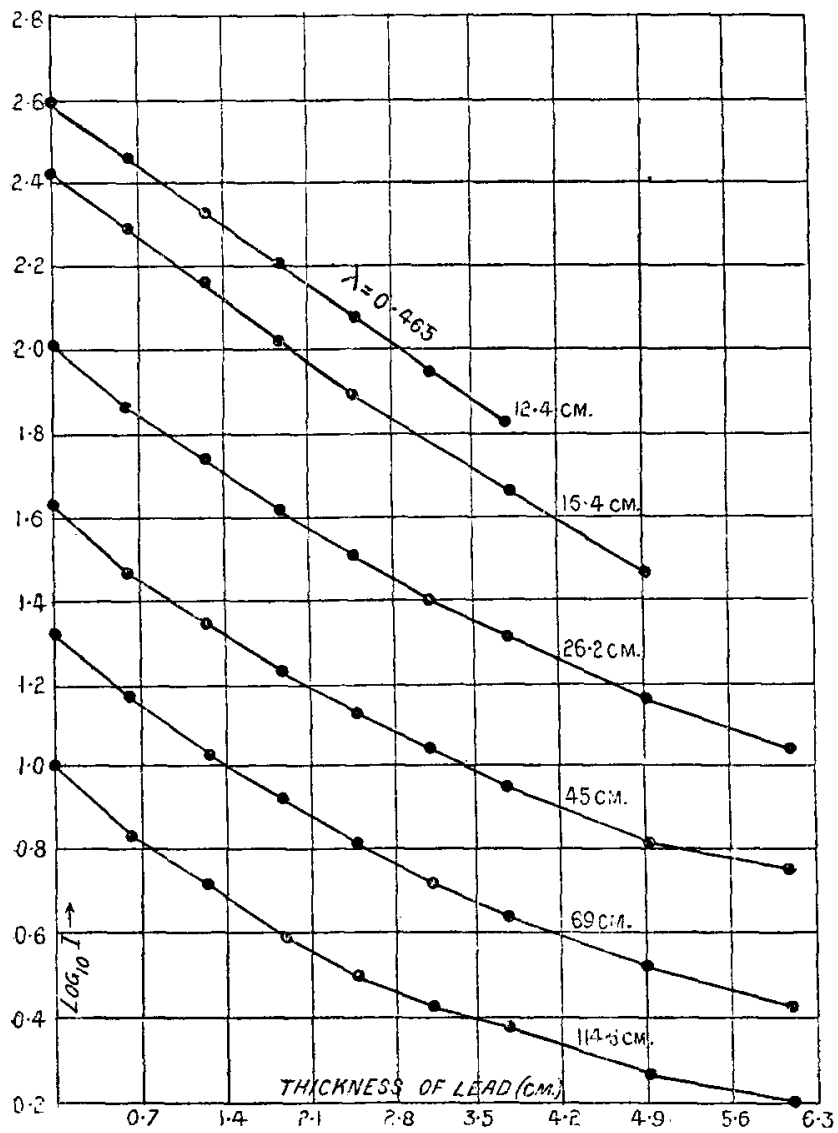

$\gamma$-Rays. Variation of Absorption with Distance of Radium from the Electroscope.

over the radium. The radium was placed below the electroscope at distances varying from $15^{\circ} 1 \mathrm{~cm}$. to $114 \cdot 6 \mathrm{~cm}$. The absorption-curves obtained are shown in fig. 2. For the 
smallest distance the curve is exponential $(\lambda=\cdot 465)$; but as the radium is removed further and further away the curves become more and more convex to the origin. From $16.4 \mathrm{~cm}$. to $114.6 \mathrm{~cm}$. the preparation is below the level of the slate bench. Although at the time it was deemed impossible for any $\beta$-radiation, secondary or primary, to penetrate the walls or windows of the brass electroscope, we very probably, owing to our experience having been mainly with the $\beta$-rays of uranium, underestimated the penetrating power of the secondary $\beta$-rays of radium. From a mature consideration of the whole of the effects obtained during the work we thought the effect may have been due to secondary $\beta$-radiation, as in no other experiments had we been able to obtain any definite evidence of secondary $\gamma$-radiation, generated by $\gamma$-rays, more penetrating than the $\beta$-rays (compare Sections $8 \mathrm{~A}$ and 9 ). When the electroscope, on the other hand, has a base thin enough to allow secondary $\beta$-radiations to penetrate it, and the radium is placed a few centimetres beneath, it was noticed that the leak was always greater with the absorbing screens directly over the radium than when they were clamped up to the electroscope. This is to be ascribed to lateral $\gamma$-radiation generating secondary $\beta$-radiation at the point when it can enter through the electroscope base.

8 A.

[Since the paper was printed we have examined more closely the question as to whether secondary $\beta$-radiation caused the effect discussed in Section 8 . The wall of the brass electroscope was thickened in places by external sheets of various metals. It was found that whereas the addition of brass up to a thickness of $3 \mathrm{~mm}$. did not affect the actual value of the leak for a fixed disposition, even thin lead-foil cut it down appreciably. Beyond $2.2 \mathrm{~mm}$. of lead no further reduction was noticed. At this stage for the particular disposition used the difference amounted to a third of the total effect. The leaks at the end of the lowest curve in fig. 2 were only one-half as great as in this case. These results taken in conjunction with those recorded in Section 10 show that the departure of the absorption-curves (fig. 2) from the straight line is to be ascribed to external secondary radiation more penetrating than the $\beta$-rays, so far as brass is concerned, but readily absorbed by lead. The choice of a thick lead electroscope in the final series of measurements described in section 10 was made from quite other considerations, but it now appears that secondary radiation effects were thus probably avoided, which might not have been the case if an 
equally thick electroscope of another metal had been employed. The work of Eve just published (Phil. Mag. 1909, xviii. p. 175), taken into conjunction with that of Kleeman, Bragg and Madsen, led him to the view that lead is peculiar in that it absorbs secondary $\gamma$-radiation and generates little or none (compare concluding paragraph of section 10).j

\section{The Effect of Secondary Penetrating Radiation.}

The absorption of $\gamma$-rays by matter may be conveniently expressed with fair accuracy by an exponential law though small departures from this law are probably always present. We think that in an unsuitable form of apparatus secondary penetrating rays play a large part in causing these deviations. We have not been able by any theory of secondary radiation to predict beforehand what variation is likely to be obtained in any ordinary case. It suffices in the first instance to suppose that the $\boldsymbol{\gamma}$-rays generate at each point in passage through matter a secondary radiation proportional in intensity to the primary, but with a different coefficient of absorption. If we assume that the rays, both primary and secondary, traverse the plate normally, the mathematical proposition is, reading thickness instead of time, formally identical to that of the theory of successive chemical changes, such, for example, as has been thoroughly worked out by Rutherford for successive radioactive changes. If $\mathrm{Q}_{0}$ indicates the initial energy of the primary beam, $Q_{t}$ the energy of the combined primary and secondary emerging from a plate of thickness $t, \lambda_{1}$ and $\lambda_{2}$ the absorption coefficients of the primary and secondary respectively, and $\kappa$ is a coefficient of transformation, representing the fraction of the absorbed primary transformed into secondary, it can be at once shown that

$$
\frac{\mathrm{Q}_{\mathrm{T}}}{\mathrm{Q}_{0}}=(1+\mathrm{A}) \epsilon^{-\lambda_{1} t}-\mathrm{A}\left(\epsilon^{-\lambda_{2} t}\right) \text {, }
$$

where

$$
\mathrm{A}=\frac{\kappa \lambda_{1}}{\lambda_{2}-\lambda_{1}}
$$

As the ionizations, not the energies, are measured, and these are directly proportional to the absorption coefficients, this must be allowed for, and we obtain

where

$$
\frac{\mathrm{I}_{\mathrm{T}}}{\mathrm{I}_{0}}=(1+\mathrm{B}) \epsilon^{-\lambda_{1} t}-\mathrm{B}\left(\epsilon^{-\lambda_{2} t}\right)
$$

$$
\mathrm{B}=\frac{\kappa \lambda_{2}}{\lambda_{2}-\lambda_{1}}
$$

and $I_{T}, I_{0}$ refer to the ionizations. 
We may merely state here that we have not yet been able to obtain any verification apart from the effects recorded in Section $8 \mathrm{~A}$ of the existence of secondary or reflected penetrating rays generated by the passage of $\gamma$-rays through matter in any of the dispositions employed. The above equations apply, of course, equally to the secondary $\beta$-radiation which is known to be generated; but the effect of this on the absorption-curve is only apparent over the same range as that of the primary $\beta$-rays, which is usually not directly investigable. Beyond this range the second term of the equation disappears, the absorption is exponential, and merely the absolute value of the ionization leak is multiplied by a constant factor. This state, by analogy to radioactive equilibrium, might be called " radiation equilibrium."

\section{The Form of Apparatus finally adopted.}

As the $\gamma$-radiation from uranium $X$ is comparatively feeble, it was important to construct the electroscope of metal which for a given volume would give the largest effect. Lead was found to be easily the best for this purpose. This is curious as precisely the opposite effect was expected. For when the absorbing plates form the base of the electroscope the leak in the instrument for equivalent thicknesses (i. e. thickness $x$ density) is least for lead. We have probably here an example of the difference discovered by Bragg and Madsen (Phil. Mag. 1908 , xv. p. 663) between the incidence and emergence secondary radiation. The emergence radiation of lead is not greatly different from that of light metals like aluminium, whereas the incidence radiation is much greater than that from aluminium. Electroscopes of lead and brass with circular cross-section and electroscopes of lead, aluminium, zinc, and cardboard with square cross-section all of the same height were compared under identical conditions of experiment. It was found that in the two lead electroscopes the ionization produced by the $\boldsymbol{\gamma}$-rays was proportional to the volume of the electroscope. Lead was easily the best, then came zinc and brass which gave about equal ionization. Cardboard lined with tinfoil came next, and lastly aluminium. The electroscopes were of varying thicknesses, but in no case was the ionization increased by increasing the thickness of the walls. The relative values of the ionization in the electroscopes were approximately:-Lead 100 , zinc 75 , brass 75 , cardboard 68 , aluminium, 57. To eliminate the possible effect of secondary rays and to secure the maximum ionization by $\boldsymbol{\gamma}$-rays a cylindrical lead electroscope with small glass windows was constructed with the following dimensions:-Inside height 
$12.8 \mathrm{~cm}$., inside diameter $9.0 \mathrm{~cm}$., wall thickness $0.65 \mathrm{~cm}$., thickness of top $1.18 \mathrm{~cm}$., thickness of base $2 \cdot 84 \mathrm{~cm}$.

The electroscope was completely surrounded by two circular screens of lead of height $12.6 \mathrm{~cm}$. and of thickness $0.244 \mathrm{~cm}$, provided with small windows cut in them. The whole was titted with a wooden stand and mounted on four brass pillars above the wooden table. With this new instrument the effect of varying the distance of the radium was again investigated in a manner precisely similar to that already described for the brass electroscope. In every case the exponential law of absorption now held even up to distances of over a metre. In contrast to the similar experiments with Wigger's apparatus, the value of $\lambda$ also only varied slightly, if at all, with the distance. The value of $\lambda(\mathrm{cm})^{-1}$ from $2 \cdot 8$ to $8.9 \mathrm{~cm}$. of lead in this series was 0.483 with the radium $13.1 \mathrm{~cm}$. and 0.480 with the radium $113 \mathrm{~cm}$. below the base of the electroscope. At intermediate distances $\lambda$ was intermediate.

The base was too thick for work with the feeble $\gamma$-rays of uranium $X$, and it was replaced by a permanent base consisting of a plate of lead $0.975 \mathrm{~cm}$. thick. With this alteration the instrument formed the standard one in all subsequent measurements. All the active preparations were placed at the uniform distance of $13 \mathrm{~cm}$. from the under surface of the base, the absorbing plates were placed directly over the active material, and the air in the electroscope was thoroughly ionized between each observation.

Before giving the final results, it is of interest to refer to some observations which show that even in this method of work a certain amount of arbitrariness is introduced into the results by the particular disposition adopted. The effect on the absolute value of the leak in the electroscope of alternately placing the same plates over the active material and against the under side of the base of the instrument was examined. For the radium $\gamma$-rays the leak was slightly less both with copper and lead when the plates were clamped up to the base. For uranium $\mathrm{X}$ the same held true except for great thicknesses of lead when the converse held. Thus for uranium $X$ the absorption curves for lead with the two dispositions actually cut one another. The effects so introduced, however, are not large, and the advantages in ease and quickness of working in placing the plates directly over the active material are very great as compared with the first method employed. At the same time we do not think that there is much to choose between the two methods from a theoretical point of view. Each is open to some objection. 


\section{Comparison of the Absorption Coefficients of the $\gamma$-Rays of Uranium and Radium.}

With the method described in last section a series of comparable measurements of the absorption coefficients of the $\gamma$-rays of uranium $X$ and radinur were finally carried out. The only difference between them is that the uranium $\mathrm{X}$ was in the form of a surface of about $30 \mathrm{~cm}^{2}$ area, while the radium constituted practically a point source. The uranium $X$ preparations employed were those of the third separation.

The results with radium are given in Table II. and fig. 3. They bear out the values of McClelland and Eve.

\section{TABLe II.-Radium $\gamma$-Rays.}

Lead Electroscope, base $\cdot 975 \mathrm{~cm}$. thick. Absorbing Plates laid directly over Radium, which was $13.0 \mathrm{~cm}$. below under surface of base. $0.47 \mathrm{mg}$. of $\operatorname{RaBr}_{2}$ used.

\begin{tabular}{|c|c|c|c|c|c|}
\hline No. & Material. & Density. & Range (cm.) & $\lambda(\mathrm{cm} .)^{-1}$ & $100 \times \lambda / d$ \\
\hline$\frac{1 .}{2 .}$ & $\begin{array}{l}\text { Mercury. } \\
\text { Lead. }\end{array}$ & $\begin{array}{l}13 \cdot 59 \\
11 \cdot 40\end{array}$ & $\begin{array}{r}34 \text { to } 3.32 \\
0 \text { to } 7.91\end{array}$ & $\begin{array}{l}\cdot 642 \\
.495\end{array}$ & $\begin{array}{l}4 \cdot 72 \\
4 \cdot 34\end{array}$ \\
\hline $\begin{array}{c}3 . \\
4 . \\
5 . \\
6 . \\
7 . \\
8 . \\
9 . \\
10 . \\
11 .\end{array}$ & $\begin{array}{l}\text { Copper. } \\
\text { Brass. } \\
\text { Iron. } \\
\text { Tin. } \\
\text { Zinc. } \\
\text { Slate. } \\
\text { Aluminium. } \\
\text { Glase. } \\
\text { Magnesia Brick. }\end{array}$ & $\begin{array}{l}8 \cdot 81 \\
8 \cdot 35 \\
7 \cdot 62 \\
7 \cdot 245 \\
7 \cdot 07 \\
2 \cdot 854 \\
2 \cdot 77 \\
2 \cdot 52 \\
1 \cdot 92\end{array}$ & $\begin{array}{l}0 \text { to } 7 \cdot 60 \\
0 \text { to } 5 \cdot 86 \\
0 \text { to } 7 \cdot 57 \\
0 \text { to } 5 \cdot 51 \\
0 \text { to } 6 \cdot 00 \\
0 \text { to } 9 \cdot 44 \\
0 \text { to } 11 \cdot 19 \\
0 \text { to } 11 \cdot 26 \\
0 \text { to } 11 \cdot 86\end{array}$ & $\begin{array}{l}\cdot 351 \\
.325 \\
\cdot 304 \\
\cdot 281 \\
.278 \\
\cdot 118 \\
.111 \\
.105 \\
\cdot 076\end{array}$ & $\begin{array}{l}3 \cdot 98 \\
3 \cdot 89 \\
3 \cdot 99 \\
3 \cdot 88 \\
3 \cdot 93 \\
4 \cdot 14 \\
4 \cdot 01 \\
4 \cdot 16 \\
3 \cdot 96\end{array}$ \\
\hline $\begin{array}{l}12 . \\
13 .\end{array}$ & $\begin{array}{l}\text { Sulphur. } \\
\text { Paraffin-wax. }\end{array}$ & $\begin{array}{l}1.785 \\
0.862\end{array}$ & $\begin{array}{l}0 \text { to } 11 \cdot 59 \\
0 \text { to } 11.39\end{array}$ & $\begin{array}{l}.0782 \\
.040\end{array}$ & $\begin{array}{l}4 \cdot 38 \\
4 \cdot 64\end{array}$ \\
\hline
\end{tabular}

Mean value of $\lambda / d(\operatorname{Nos} .3$ to 11$)=0399$.

The results with uranium $\mathrm{X}$ are given in Table III. and fig. 4 (pp. 646, 647).

From the curves (figs. 3 and 4 ) it can be seen how nearly the exponential law is followed in the case of all substances. Only the first points on the curve, with zero thickness, show slight irregularities. There is no evidence of the existence of the second negative exponential term, showing that if secondary rays are generated by the $\gamma$-rays of either uranium or radium, they are unable to penetrate $1 \mathrm{~cm}$. of lead. Moreover the value of the absorption coefficient is for all substances of average density independent of the nature of the substance. 
Fig. 3.

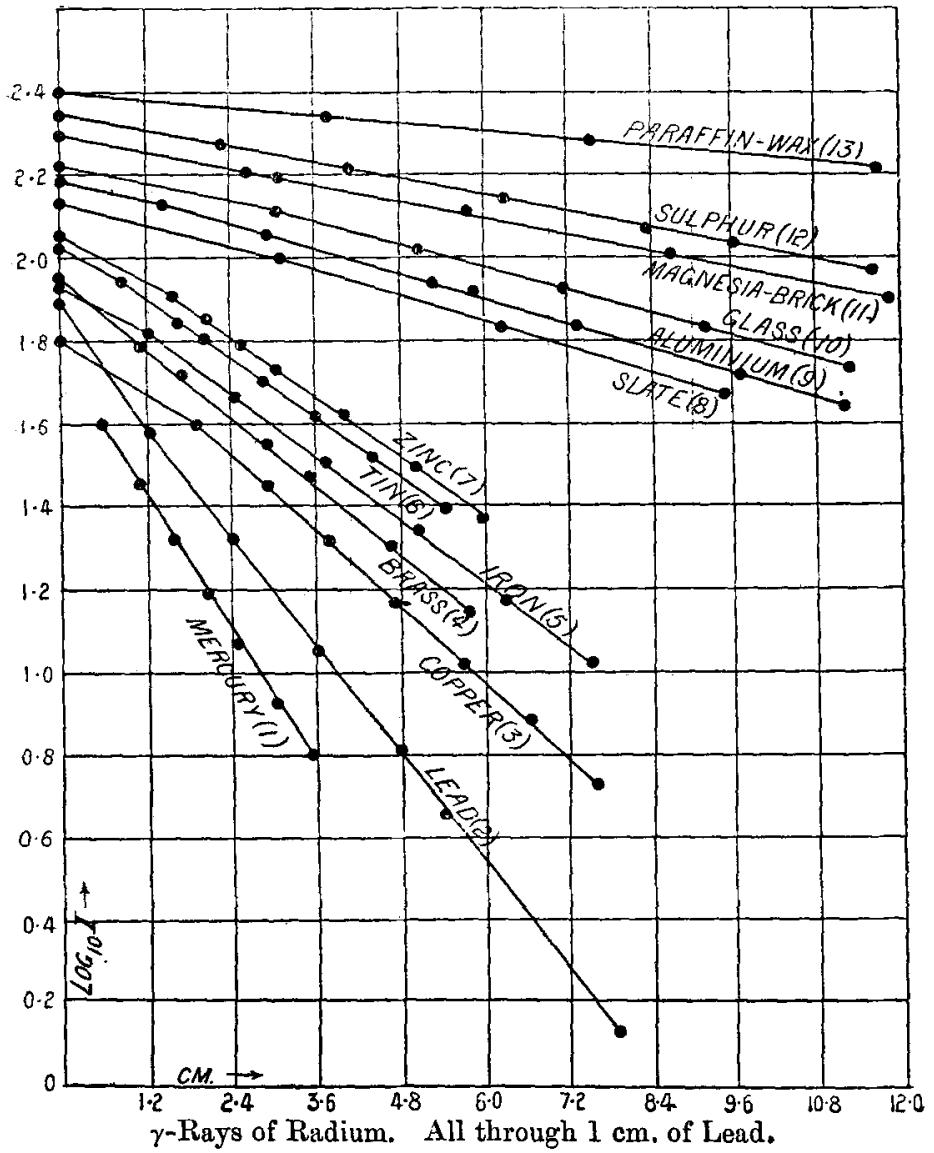

The mean value of $\lambda / d$ for all substances having a density between the range of from $2 \cdot 6$ to $8 \cdot 8$ is for radium $\cdot 040$, and for uranium $X \cdot 047$. It may be noted that the deviations from the mean value are, considering the nature of the experiment, very small indeed. This is largely due to the precantions taken each time to secure the minimum leak referred to before.

Thus $\lambda / d$ for uranium $X$ for zinc gave a value of $\cdot 0465$ twice on different occasions. Repeating the experiment under exactly similar conditions, on the same day as one of the measurements, except that the leak was taken without thorough ionization of the air in the electroscope before each 
TABLE III.-Uranium X $\gamma$-Rays.

Disposition as in Table II. except that the Uranium X occupied a surface of about $30 \mathrm{sq}$. $\mathrm{cm}$.

\begin{tabular}{|c|c|c|c|c|c|c|}
\hline No. & Material. & Density. & Range (cm.). & $\lambda(\mathrm{cm} .)^{-1}$. & $100 \times \lambda / d$. & $\frac{\lambda \operatorname{UrX}}{\lambda \mathbf{R a}}$. \\
\hline $\begin{array}{l}1 . \\
2 .\end{array}$ & $\begin{array}{l}\text { Mercury. } \\
\text { Lead. }\end{array}$ & $\begin{array}{l}13.59 \\
11 \cdot 40\end{array}$ & $\begin{array}{c}343 \text { to } \\
0 \text { to } \\
4: 535\end{array}$ & $\begin{array}{l}.832 \\
.725\end{array}$ & $\begin{array}{l}6 \cdot 12 \\
6 \cdot 36\end{array}$ & $\begin{array}{l}1 \cdot 297 \\
1 \cdot 465\end{array}$ \\
\hline $\begin{array}{l}3 . \\
4 . \\
5 . \\
6 . \\
7 . \\
8 . \\
9 .\end{array}$ & $\begin{array}{l}\text { Copper. } \\
\text { Brass. } \\
\text { Iron. } \\
\text { Tin. } \\
\text { Zine. } \\
\text { Slate. } \\
\text { Aluminium. }\end{array}$ & $\begin{array}{l}8 \cdot 81 \\
8 \cdot 35 \\
7 \cdot 62 \\
7 \cdot 245 \\
7 \cdot 07 \\
2 \cdot 854 \\
2 \cdot 77\end{array}$ & 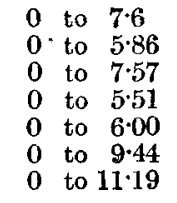 & $\begin{array}{l}\cdot 416 \\
.392 \\
\cdot 360 \\
\cdot 341 \\
\cdot 329 \\
\cdot 134 \\
\cdot 130\end{array}$ & $\begin{array}{l}4 \cdot 72 \\
4 \cdot 70 \\
4 \cdot 72 \\
4 \cdot 70 \\
4 \cdot 65 \\
4 \cdot 69 \\
4 \cdot 69\end{array}$ & $\begin{array}{l}1 \cdot 186 \\
1 \cdot 208 \\
1 \cdot 183 \\
1 \cdot 212 \\
1 \cdot 183 \\
1 \cdot 13 i 3 \\
1 \cdot 169\end{array}$ \\
\hline $\begin{array}{l}10 . \\
11 . \\
12 . \\
13 . \\
14 .\end{array}$ & $\begin{array}{l}\text { Glass. } \\
\text { Magnesia Brick. } \\
\text { Sulphur. } \\
\text { Paraffin-wax. } \\
\text { Pine-wood. }\end{array}$ & $\begin{array}{l}2 \cdot 52 \\
1.92 \\
1 \cdot 785 \\
0 \cdot 862 \\
0.386\end{array}$ & $\begin{array}{l}0 \text { to } 11 \cdot 26 \\
0 \text { to } 11 \cdot 86 \\
0 \text { to } 11 \cdot 59 \\
0 \text { to } 11 \cdot 39 \\
0 \text { to } 12 \cdot 51\end{array}$ & $\begin{array}{l}.122 \\
.0917 \\
.0921 \\
.0433 \\
.02926\end{array}$ & $\begin{array}{l}4 \cdot 84 \\
4 \cdot 78 \\
5 \cdot 16 \\
5 \cdot 02 \\
7 \cdot 58\end{array}$ & $\begin{array}{l}1 \cdot 160 \\
1.207 \\
1.178 \\
1.082 \\
\ldots \ldots\end{array}$ \\
\hline
\end{tabular}

Mean value of $\lambda / d$ (Nos. 3 to 9$) \cdot 0470$.

$$
, \quad \frac{\lambda \mathrm{UrX}_{\mathbf{r}}}{\lambda \mathrm{Ra}} \quad, \quad 1 \cdot 181 .
$$

observation, gave the value 0.0441 for $\lambda / d$, a value 5 per cent. less than the former value. Equally good experiments with the same metals in Table I. gave values for $\lambda / d$ differing by 8 per cent. Now for uranium $\mathrm{X}$ the extreme values of $\lambda / d$ for bodies within the density range specified are $\cdot 0465$ and .0472 , which is only a variation of about 2 per cent. For radium the extremes are $\cdot 0387$ and $\cdot 0414$.

For substances of density beyond the limits $2: 6$ to $8 \cdot 8$ on either side the values of $\lambda / d$ are considerably larger, the departures being more apparent for the case of uranium $\mathrm{X}$ than for radium. These departures seem to be genuine, for all the results showing them have been repeated, and the same or very similar results obtained. They probably have their origin in the disposition used. Thus in the original work with uranium $X$ (Table I.), when the absorbing materials were clamped up, $\lambda / d$ was, on the whole, fairly constant over the entire range from mercury to pine-wood, with a mean of 0536 , while in the later work both with radium and uranium $X$, in which the materials are laid directly on the source of radiation, differences appear. The general arrangement of the experiment and the method of working in the former case, however, were much less accurate 
than in the latter. A determination of $\lambda$ for lead with uranium $\mathrm{X}$ with the new disposition and method of working

Fig. 4.

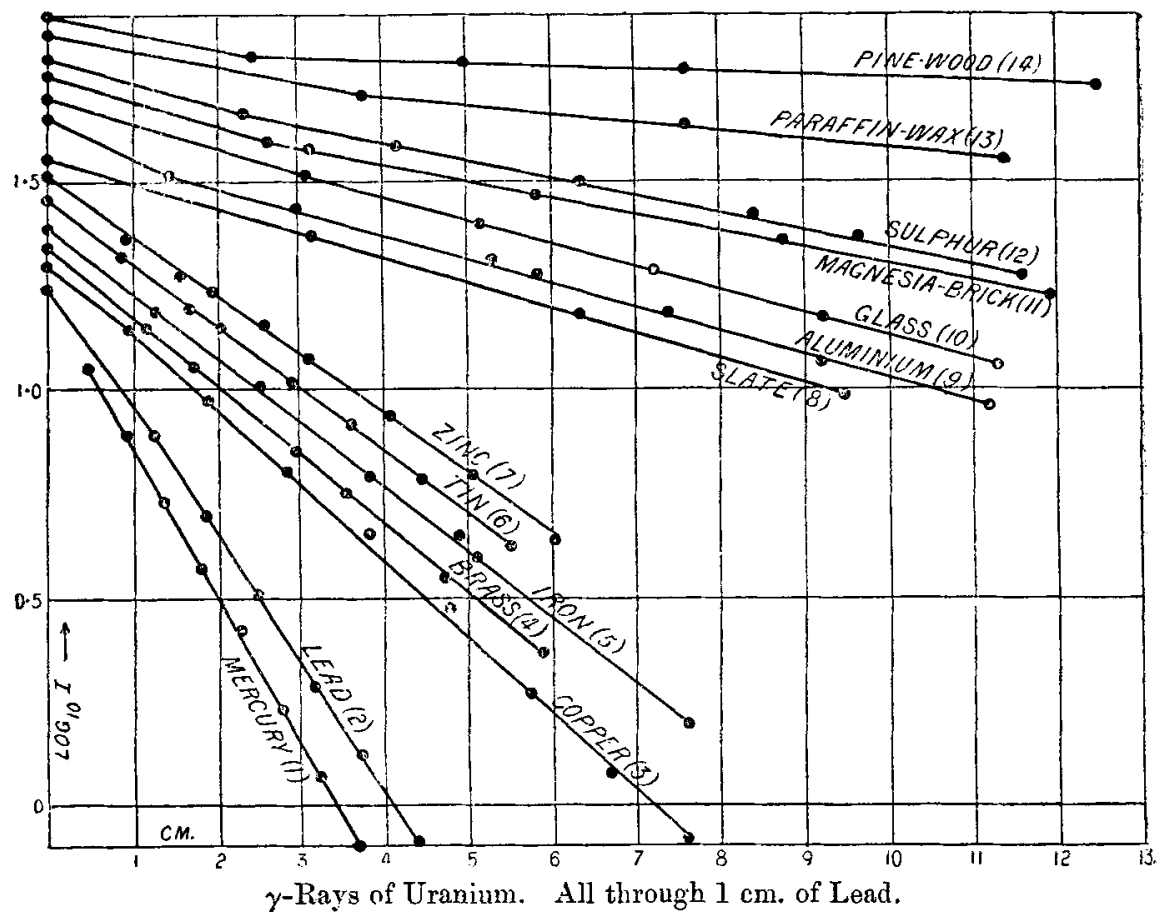

except that the metal was all clamped to the base of the electroscope gave a value 0.66 , which is much nearer to the value given in Table I. than to that in Table III.

Considering now the ratio of the absorption coefficients for uranium and radium shown in the last column of Table III., it will be seen that, excluding the two heaviest substances, mercury and lead, and the two lightest, sulphur and paraffinwax, the mean ratio is $1 \cdot 182$, and the actual values are wonderfully close to this mean. If we exclude also slate, which is an indefinite sort of material, the extreme variation from the mean value is only 2 or 3 per cent.

[It is very interesting to note that the division of the subm stances in Tables II. and III. into three groups, according to the values obtained for $\lambda / d$, is practically the same as the division made by Kleeman for totally distinct reasons in his study of the secondary radiations generated by $\gamma$-rays. (Compare Phil. Mag. 1908, xv. p. 644, Tables I. and II.)] 
Lead is entirely anomalous with the value of the ratio $1 \cdot 465$, and this no doubt, as explained, is to be attributed partly to the disposition employed, and possibly also to the fact that the measurements were done in a lead electroscope. It is rather curious that lead, of all metals, seems in many ways to be the most unsuited for accurate measurements of the absorption of $\gamma$-rays, and yet it is the one which we, in common with previous investigators, have worked with most. We have noticed repeatedly that it is more difficult to obtain consistent results with lead as the absorber than with any other material. This is partially perhaps, but not wholly, due to its own high natural radioactivity, necessitating frequent redetermination of the natural leak. If we wer repeating the work we should use by preference another metal in many of the measurements described in the first part of the paper.

\section{Summary of Results.}

1. The $\gamma$-radiation of uranium $\mathrm{X}$, separated from 50 kilograms of uranyl nitrate, has been compared with the $\gamma$-radiation of radium, and it is concluded that the $\beta$ - and $\gamma$-radiations are probably not, as hitherto assumed, interdependent.

2. The initial $\gamma$-radiation of the uranium $\mathrm{X}$ in equilibrium with 1 kilogram of uranium (element) is equal to that of 0.015 milligram of a particular sample of a radium compound, which may be provisionally regarded as containing $66^{\circ} 6$ per cent. of radium.

3. The ratio of the $\beta$ - to the $\gamma$-rays of uranium $\mathrm{X}$ is 62 when the same ratio for radium $\mathrm{C}$ is taken as unity, the $\gamma$-rays being measured through $1 \mathrm{~cm}$. of lead. Correcting for the absorption in the lead, and assuming the rays to be homogeneous in each case, the value of the ratio for uranium is 50. When the $\gamma$-rays are measured through $0.6 \mathrm{~cm}$. of aluminium, so as to admit any soft $\gamma$-radiation if present, the ratio for uranium is 18 , not correcting for absorption. It is not yet decided whether a soft primary $\gamma$-radiation of uranium exists.

4. The $\gamma$-radiation accompanies the $\beta$-radiation of uranium $X$, and decays at approximately the same rate.

[4a. Later results give 0.028 (day) ${ }^{-1}$ for the value of $\lambda$ determined from the decay of the $\gamma$-rays. This is about 10 per cent. less than the known value derived from the decay of the $\beta$-rays.]

5. For thicknesses less than $1 \mathrm{~cm}$. of lead, or its equivalent, the absorption of the uranium $\gamma$-rays does not follow any 
simple law. For greater thickness the absorption is quite exponential, and nearly or wholly independent of the nature of tho substance traversed, being proportional to its density. In one series the absorbing plates themselves formed the base of the electroscope, and the mean value of $\lambda / d$ was 0.0536 .

6 . In a thick-walled lead electroscope with a base $1 \mathrm{~cm}$. thick, the absorbing plates being placed directly over the preparation, the absorption both for uranium aud radium was strictly exponential. The value of $\lambda / d$ for all but the heaviest and lightest substances was 0.047 for uranium and 0.040 for radium, the ratio being $1 \cdot 18$. Lead appears exceptional under these conditions, and the value of $\lambda / d$ is 0.0636 for uranium $\gamma$-rays, and $0 \cdot 0434$ for radium $\gamma$-rays, the ratio being $1 \cdot 465$. In the first disposition lead appears quite normal.

7. Some evidence of the existence of a secondary radiation more penetrating than $\beta$-rays, generated by the $\gamma$-rays, has been obtained, but almost certainly none exists able to affect measurements taken through $1 \mathrm{~cm}$. of lead.

8. The $\gamma$-ray ionization is not in all cases constant, but suffers a progressive increase with certain dispositions, from a minimum to a maximum about 12 per cent. greater, when consecutive observations are made without pause. The effect depends upon the presence or absence of a charge on the leaf system; for if the charge and the ionization are maintained, the rate of leak tends towards a maximum ; while if the ionization is maintained for a sufficient period after the charge has been dissipated the rate of leak becomes a minimum again.

Physical Chemistry Laboratory,

University of Glasgow.

June 1909.

[Additions made August 1909.]

LXVI. The Kinetic Energy of the Positive Ions emitted from various Hot Bodies. By F. C. BRown, Ph.D.; Porter Ogden Jacobus Fellow, Princeton University *.

7 HIS paper describes an investigation of the kinetic energy of the positive ions from gold, silver, palladium, tantalum, nickel, platinum, aluminium phosphate, osmium, tungsten, and iron.

It was shown in a paper by Richardson and Brown $\dagger$ that if the kinetic energy of the ions is due solely to thermal

* Communicated by Prof. O. W. Richardson.

+ Phil. Mag. [6] vol. xvi. p. 353 (1908).

Phil. Mag. S. 6. Vol. 18. No. 106. Oct. 1909. 